\title{
Cultural Harm and Engaging the Limits of a Right to Cultural Identity (Andrew Fagan)
}

Introduction

Cultural diversity remains a key challenge for the justification and application of universal human rights norms. Many human rights theorists and practitioners insist that the continuing normative legitimacy of human rights norms depends upon the doctrine's capacity to accommodate a very broad range of culturally-based ways of being and believing. In order to enjoy genuinely universal credibility, human rights are required to affirm the manifest diversity of human life, which, in turn, entails a thorough engagement with the differing empirical realities of suchhuman life. A core component of this affirmation of diversity is the defence of Commented [JF1]: Such life? Avoids repetition the right torights to cultural identity. So-called cultural rights have attracted renewed interest in recent years, in part because they appear to offer the promise of reconciling respect for universal human rights with a similar respect for cultural diversity. While recognising the growing need for human rights norms to constructively engage with cultural diversity, this paper, nevertheless, strikes a cautionary tone, and identifies one area in which the limits of the legitimate application of rights to cultural identity requires greater, more critical, attention. Specifically, the paper focuses upon the right of exit. The right of exit appears to provide an instrument by which legislative authorities can largely avoid the politically and conceptually fraught challenge of normatively evaluating traditions and practices, found within various cultural communities under their jurisdiction. The individual members of such communities are afforded the principal say over their continuing adherence to the community's ways of being and believing. In this way, the right of exit appears to offer a normatively sound basis for a rights-based approach to cultural diversity, insofar as it enables, simultaneously, respecting individuals' core normative commitments and respecting the terms of the various relationships 1| P a g e 
which define and bind their cultural membership. The legitimacy of any given cultural community mayy thereby be largely based upon individuals' subjective deliberations. This paper will argue that a human rights-based evaluation of rights to cultural identity cannot rely entirely upon the principle that an individual's- lack of overt opposition to key defining and binding relationships, provides a secure basis for a rights-based response to cultural identity. By analysing the effects of some culturally-based practices and beliefs upon domestic abuse, the paper will demonstrate that some domestically-abused women's ability to exercise their right of exit has been effectively-severely disabled by the highly restrictive identities which their communities accord to them. It will be argued that, in some cases, the conditions which underpin such restrictive identities violate core human rights norms.

Specifically, the- paper begins by considering anthe appeal to the relative universality of human rights norms as a means for reconciling human rights and cultural diversity. Cultural rights are then examined as a key element ofim the on-going concern of human rights theorists and defenders for recognising the value of cultural identity and belonging. The analysis-examination of cultural rightss willparticularly focus particularly upon ascribed identities as a core concern for those who defend the need for cultural rights. The discussion then focuses upon the conditional character of cultural rights, before proceeding to engage with the right of exit as a potential basis for grounding a commitment to recognising both cultural belonging, and, a continuing commitment to upholding individual sovereignty. The paper then tmms te presents and analyses obstacles to individuals' exerciseing of the right of exit, and outlines a condition of individuals'pays particular attention to a condition of being unable to leave. The paper considers a range of possible objections to this conditionsuch a claim and concludes by arguing that determining the grounds and limits to rights to cultural identity must include a due concern for the invidious forms of cultural harm. 
3| Page 
Human rights and recognizing cultural diversity: relative universality

Long periods of strain and discord have beset theThe marriageunion -between cultural diversity and human rights norms has enderred leng periods of strain and discerd. The ideals upon which human rights norms have been conventionally based have attracted consistent criticism. Many have argued that personal autonomy, moral equality, and, even human dignity, are either too conceptually indeterminate to ground anything as tangible as international instruments of human rights law, or are ideals which originate in, and continue to reflect, the parochial and partial ways of being and believing which Western intellectual and political elites have typically (though all-too oftenand not always inconsistently) espoused." There exist many longestablished cultural communities and civilisations which do not recognise the normative force of autonomy, equality, or the inherent dignity of all human beings. For some critics of human rights the existence of such human communities justifies and entails a rejection of what others defend as the culturally transformative potential of human rights. Through an appeal to a variously-conceived notion of cultural sovereignty, many defenders of such communities have argued that attempts at converting the members of such communitiesgroups to the doctrine of human rights is merelyamounts to the latest manifestation of cultural imperialism. On this view, the promotion of human rights and the unconditional promotion of cultural diversity are mutually exclusive. - This approach has been extensively criticised, and is affirmed by only a small number of theorists and practitioners. ${ }^{\text {iii }}$

While its most uncompromising claims have not been widely endorsed, some elements of the relativist cultural critique of human rights continue to influence the global human rights community and its approach to cultural diversity. Thus, many theorists and practitioners who are committed to the universal validity of human rights norms have, nevertheless, embarked upon a process of critical reflection upon the challenges which the recognition of sing cultural diversity raise for the founding and applying of human rights norms amidst diversity. ${ }^{\text {iv }}$ This 
attempt to reconcile human rights with respect for cultural diversity extends to include theoretical and practical initiatives, ranging from political philosophers' effortattempts to reestablish human rights upon non-parochial normative foundations, to numerous institutional statements and declarations which proclaim the virtuous circle of human rights and cultural diversity. A discernible trend within human rights philosophy is towards paring down the catalogue of human rights to those which sufficiently reasonable ${ }_{2}$ (or at least decent) peoples and individuals, might hypothetically endorse within the context of otherwise profoundly diverse ways of being and believing. Within institutional circles, the prevailing trend has included the formulation of various human rights declarations which explicitly address what

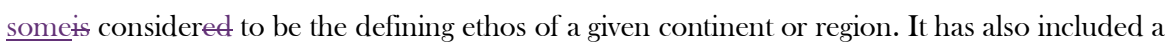
renewed interest in so-called cultural rights and the broader field of rights to cultural identity. Against those who argued that culture was, at best, irrelevant to defining the basis and content of human rights, and those others who insisted that recognising the determinative properties of culture entailed the rejection of the universal validity of human rights, there now exists a third constituency which insists that it is possible to enjoy the best of both worlds: to simultaneously affirm human rights and cultural diversity. After Jack Donnelly, I refer to this constituency as espousing a relative universalist understanding of human rights."

\section{Cultural rights: an expanding generation}

A key feature in the relative universalist reconciliation of human rights with cultural diversity consists of a renewed appreciation for what was once considered to be a poor relation within the family of international human rights: the category of cultural rights. While cultural rights have been integral to international human rights law from the very beginning of the- modern UN's-human rights system, their conventional designation as the so-called 'third generation' of human rights, underlines the difficulties their defenders have typically encounteredxperienced in their attempts at securing others' recognition of cultural rightsthem as fundamental human 
rights. However, the status of cultural rights has been enhanced through a series of significant institutional initiatives over the past three decades or so. Thus, the silo of internationally recognised cultural rights has been widened and deepened by the establishment of regional human rights declarations, such as the African Charter of Human and Peoples Rights (1986), the Cairo Declaration on Human Rights in Islam (1990), and, most recently, the ASEAN Human Rights Declaration (2012). In their respectively differing ways, each of these regional initiatives attempts to interpret universal human rights norms in ways which support and coincide with what is imagined to be the prevailing cultural ethos of each geo-cultural space. In addition, the UN has developed a series of human rights declarations which explicitly espouse the cultural rights of groups such as indigenous peoples and other minorities across the globe. The Vienna Declaration and Programme for Action (1993) has reaffirmed the UN's commitment to protecting cultural rights. In a direct attempt to counter the claim that a commitment to human rights divides rather than unites civilisations, UNESCO has published a Declaration on Human Rights and Cultural Diversity (2001).- In 2009 the UN General Assembly established a mandate of the special rapporteur for cultural rights. Within regional human rights systems the rights of national minorities have been recognised by the Council of Europe's Framework Convention for the Protection of National Minorities (1995), which adds to the European Convention of Human Rights and its recognition of cultural rights under Article 14. The Inter-American Court of Human Rights has developed a protective regime for minority rights under Article 21 of the Inter-American Charter of Human Rights. Finally, cultural rights have been espoused by various civil society initiatives such as the 2005 Yogakarta Principles which are concerned with international human rights law covering sexual orientation and gender. The undeniablesheer importance of human beings' access to, and enjoyment of, an extremely broad range of essentially cultural resources and goods is now unequivocally established within international human rights law. 
7| Page 
Access to one's own culture: rights to ascribed identities

Underlying the vigorous development of cultural rights is a vast body of empirical evidence which demonstratestestifies the extent to which systematic discrimination and inequality targets victims' core identities and beliefs. Very few, if any, of us suffer discrimination because we are perceived as bearers of a faculty for pure reason or as the disembodied subjectseiphers of natural law philosophy. Protecting the human rights of those who suffer discrimination and inequality because of others' vilification of their cultural communities' ways of being and believing, thus requires foregrounding the core attributes of the targeted identities. Specific cultural rights to language, ethnicity, religion, gender, and the like, seek to enable some to possess and express the identities which others' have sought to oppress or, in the very worst cases, eradicate.

A significant part of the justification for the need for such positive protection rests upon recognising that many such identities can be integral to the deepest commitments of thosemany human beings who adhere to them. Justifications for cultural rights must not be confused with cosmopolitanism's vision of individuals' identities as an amalgamation of diverse constellations of cultural elements and traits, which are, in some sense, consciously fashioned and constructed by individuals themselves. ${ }^{\text {.ii }}$ In stark contrast, most defenders of cultural rights argue that many core elements of many individuals' identities are neither particularly malleable nor consciously fashioned. Cultural rights are required precisely because many of us cannot simply renounce our culturally-derived identities and the commitments they are based upon. Such rightsThey draw attention to the harms suffered by many individuals who have been denied opportunities to speak their own language, worship their own idols $s_{2}$ and generally commune with their own kind. All of which speaks to the fundamentally ascribed character of personal identity for many who seek the protection of cultural rights. ${ }^{\text {ix }}$ Many forms of human relationships and communality will be adequately covered by associative rights, the foremost example of which is 
such as, for example, freedom of association and its emphasis upon the essential voluntariness of many of our commitments and relationships.such asseciations. Cultural rights, however, testify to the limitations of seeking to found all relationships and communality upon such a model. Many individuals' sense of self-worth and dignity are dependent upon enjoying access to their own, distinctive and non-substitutable communities. The growing body of internationally recognised human rights instruments speaks to the hopes of countless numbers of communities who wish to protect their beliefs, traditions and practices from external interference. Cultural rights offer an alternative to the Hobson's choice scenario which has far too often accompanied many peoples' exposure to homogenizing forms of globalisation. By supporting communities' attempts to protect their own distinctive identities, cultural rights also aimserve to harmonise a commitment to human rights, with athe furtherance of cultural diversity.

\section{The conditionality of cultural rights}

Cultural rights are indispensable to many peoples' enjoyment of their own distinctive identities.

However, as a sub-category of human rights more broadly, cultural rights are neither absolute nor intrinsically valuable. Despite some theorists' insistence that the espousal of cultural diversity entails affirming a principle of cultural equality, cultural rights cannot be extended to protect all formally-established cultural traditions and practices, if they are, at the same time, are meant to be part of a human rights framework..$^{*}$ There are identifiable cultural traditions, practices and beliefs which are manifestly incompatible with existing human rights standards and which should not enjoy-enjoy any form of human rights protection.

The possibility of some cultures harming some of their members is recognized by various human rights legal instruments and regional conventions, and is a particular concern within the field of women's human rights. Thus, the UN Convention on the Elimination of all Forms of Discrimination Against Women (CEDAW) focuses extensively on the wrongfulness of many

Commented [FF13]: (I think you need a qualification like this for this claim to hold true.)

(Should the footnote be moved to the comma after 'equality'? Otherwise there is ambiguity as to what it refers to.)

Commented [FF14]: An example of one such manifest incompatibility would help here. (What follows gives some context from internal human rights law, but remains pretty abstract, so a concrete example would help.) 
established cultural practices. The CEDAW's response to the place of culture in human rights makes a fundamentally important contribution to the understanding of the sources of human rights violations, by extending its focus beyond state institutions and actions by state bodies.

Thus, Article 1 of the CEDAW extends the concept of discrimination beyond the public sphere and into social and cultural domains. Article 2(f) more specifically identifies states parties' obligations to combat discrimination found within various cultural customs and practices. In this way, the CEDAW legally recognizes the iconic feminist insight, that the 'personal is political', and thereby draws the cultureal sphere into the human rights regulatory domains. Subsequent to the Convention, the CEDAW's Committee -- through General Recommendation 19 -- drew specific attention to the role played by traditional values, in the eentinuing discrimination and oppression many women across the world continue to suffer from. While the CEDAW sets a vital precedent in identifying potential forms of cultural harm, other UN human rights bodies have focused upon the importance of so-called traditional cultural and religious values, ${ }_{2}$ and their impact upon human rights. Thus, the Human Rights Council (HRC) recently initiated a specific study into the role of traditional values and human rights, and concludedconcluding that some such values are harmful to the more vulnerable and marginalised members of some communities, ${ }_{2}$ and reasserted reasserting that traditional values can never be legitimately elevated above human rights commitments. ${ }^{\text {i. }}$ Beyond the CEDAW and the HRC, other international initiatives recognize the harmful potential of many cultural practices, as evidenced by the Copenhagen Convention (1990), the Vienna Declaration (1993), and the Beijing Platform for Action on Women's Rights (1995). Identifying some cultural communities' specific traditions, practices and beliefs, as being harmful to the human rights of some of their members, provides the key ground-for specifying the limits of a human right to cultural identity.

Hoping for too much and the potential appeal of a right to exit ${ }^{\mathrm{xi}}$
Commented [FF15]: (This would resolve the ambiguity I noted in the earlier set of comments.) 
The self-assurance and general airsense of certainty which characterise some human rights supporters' specifications of the limits of rights to cultural identity, and the distinctly more conditional celebration of cultural diversity this entails, will resonate strongly with many peoples' understanding of human rights as a fundamental tool for combatting injustice and oppression. However, others argue that the need to secure a sustainably normative agreement for human rights norms amidst extensive cultural diversity, entails justificatory approaches which are significantly less beholden appeal to thefar less normatively substantive criteria than those which instruments such as the CEDAW are based upon. On these alternative views, confronting diversity precisely entails that the global human rights community should not continue to hope for too much. ${ }^{\text {xiii }}$ For some, a continuing commitment to substantive gender equality as a key human rights norm places human rights at odds with very many established cultural ways of being and believing, and thereby threatens to undermine the moral appealutherity of human rights within such communities. ${ }^{\text {iv }}$ It is thereby argued that, by insisting upon gender equality as a non-negotiable human rights norm, some within the human rights community run the risk of setting normative aspirations too high; of hoping for too much from human rights.

Philosophical calls to limit the normative substance of human rights are not likely to induce a corresponding unpicking of international human rights law, nor lead to the abandonment of the CEDAW and other instruments which some states have taken issue with. ${ }^{\mathrm{x}}$ However, the defence of human rights has nothing to gain by complacency, and othergenuine threats to the continuing authority of the global human rights system are-readily identifiablenet difficult te find: the regional, and increasingly global, influence of China, with and rights; the renewed support enjoyed by anti-immigrant political parties in many Western democracies; and a growing perception among many electorates that support for human rights is a principle which has been foisted upon them by liberal, unrepresentative elites. We may not 
be experiencing the so-called end-times or twilight of human rights ${ }^{\text {si }}$, but some philosophers' further weight to an emerging trend which aims at vernacularizing human rights norms. The potential value of according far greater significance to the right of exit should be understood within this context.

\section{The exit option: leaving it up to individuals to decide}

Vernacularizing human rights norms aims at re-establishing the moral authority of human rights upon foundations which are, simultaneously, acceptable to a broad and diverse range of different ways of being and believing ${ }_{2}$ whilst retaining a sufficient concern for protecting individuals from oppressive forms of power. It hardly needs stating that such an objective is conceptually and, practically, profoundly complex. However, precedents exist.

The right of exit has gained prominence over the past two decades precisely as a response to the challenge of regulating culturally diverse societies. Its appeal extends across different traditions of political and legal philosophy and it is a firmly established legal instrument within many jurisdictions. ${ }^{\text {sii }}$ The right of exit option appears to offer many advantages for a human rights-based attempt to constructively respond to cultural diversity within sovereign nationstates. ${ }^{\text {viii }}$

a) It is a right and is thereby entirely consistent with a rights-based approach to meeting this challenge.

b) Many, particularly communitarian-minded, theorists argue that the right of exit offers sufficient assurance for those who worry that the collective rights entailed by a right to cultural identity might result in unduly restricting the basic liberty of some of the 
community's members. Thus, Bhiku Parekh and David Ingram insist that recognizing a right to cultural identity entails the acceptance of some forms of institutionalised collective rights, but that the right of exit enables dissident members to simply leave. .ix $^{\text {ix }}$

c) It ostensibly complies with a core and widely-endorsed normative commitment which upholds individual deliberation as a fundamental good and serves to afford due respect to individuals as decision-makers.

d) While endorsing the right of exit doesn't entail taking a normative position on the value of cultural identity, for for many it appears- to be entirely consistent with recognizing the importance of cultural belonging to individuals.

e) The right respects any given cultural community's authority to maintain their own identity against internal dissidents who are in the minority.

f) It enables the state to avoid taking a comprehensively evaluative standpoint on the question of the value of individual cultures. Thus, while some advocates of a right of exit seek to formulate it in terms which entail the necessity of a prior commitment to personal autonomy or substantive equality, others formulate the right in ways which rest upon the empirical fact of whether or not any given individual wishes or does not wish to exit a community: the grounds for its exercise are thereby entirely subjective and are determined by individuals' expressed wishes and preferences alone. The state is thereby not required to take an independently evaluative position on the necessary grounds for exercising the right. ${ }^{\text {xii }}$

For those seeking to vernacularize human rights principles in orderse as to better respond constructively to cultural diversity, the right of exit appears to provide a powerful resource and a potential ground for identifying the criteria for determining the value of any given cultural community: leave the task of judging cultures to their individual members and trust in their ability to know their own minds. The right of exit-does appears to offer a powerful instrument 13 | Pag e 
for the purpose of re-shaping human rights amidst diversity. A core motivation would be to extend the ethical appeal of human rights in such a way as to counter the claims that human rights principles unduly reflect Western, liberal values and ideals. In seeking to re-establish human rights on grounds which do not ultimately depend upon support from partial ideals, the right of exit approach obviously entails an acknowledgement of the right of many non-liberal cultures to exist. The very designation of some of these cultures as 'non-liberal' raises the possibility that the protection of some of their defining traditions, practices and beliefs, may require the suspension of some of their members' human rights, especially, for example, some of the rights enshrined within the CEDAW. ${ }^{\text {xii }}$ On the face of it, this implication might cause some human rights defenders significant anxiety. Against this, maintaining the individual's right to exit any community they have come to disapprove of, offers apparent reassurance against the prospect of cultural communities being afforded a carte blanche to oppress some of their members. ${ }^{\text {.ivi }}$ The right thereby seeks to uphold what is widely acknowledged as a fundamental value, which has profoundly influenced the development of human rights: individuals' capacity for normatively deliberating upon their own commitments and core preferences.- From this, one can derive the following maxim: that if individuals do not seek to leave their cultural communities then there can be no legitimate basis for external interference or intervention within such communities. The individual right of exit might thereby become recognized as a core human right withinwithin -a complex and diverse global order. 


\section{On being unable to leave}

Combining a right to cultural identity and a right of individual exit, under a single normative perspective, raises an interesting and highly importantsignifieant issue. Recall that the strongest arguments supporting rights to cultural identity, focus upon ascribed forms of identity: ways of being and believing which many individuals themselves consider as, to be_effectively, irrevocable. However, the possibility of exercising the right of exit necessarily entails that individuals are capable of becoming estranged and alienated from such communities. In many cases the capacity to step back from one's culturally-derived commitments and beliefs will be retained. Under such circumstances it is entirely reasonable that the commitments of those who choose not to leave should be respected. Even, perhaps especially, where, what they continue to affirm might appear to many outsiders as potentially intolerable. Individual sovereignty takes precedence. However, this approach rests upon an assumption that all of the individuals who have not sought to exit their communities may thereby be understood to have affirmed the community's ways of being and believing. That not saying "no" amounts to consent. While the principle of respecting individuals' normative deliberations is central to the philosophy underlying both human rights norms and the appeal to a right of exit as a basis for regulating cultural diversity, it should not be universally upheld - or so I argue. Setting the limits to a right to cultural identity upon the right of exit will, inadvertently perhaps, contribute to the persistence of ways of being and believing which are significantly harmful for some individual members. Moreover, in some instances, the right of exit will not suffice to prevent the harm, because what is harmed is precisely individuals' capacity to effectively initiate any such course of action: they are largely unable to say "no". Some individuals' lack of overt opposition to their cultural fate is a consequence of the harm they are exposed to. A principle of respecting this lack of opposition is to respect cultural conditions which expose some individuals to intolerable wrongs and mistreatment. 
An established body of research has identified a socio-psychological phenomenon by which many women do not persistently oppose or object to what may reasonably be considered to be culturally intolerable practices and traditions, such as marital battering, dowry violence, the denial of legal standing generally to unmarried women, and genital surgeries. ${ }^{\text {xwi }}$ The research indicates that many victims of such practices are effectively incapable of challenging or avoiding their fate. I shall examine this phenomenon by focusing upon domestic abuse. One particularly significant area concerns domestic abuse.

Domestic abuse is a universal phenomenon and affects women and girls across a vast range of social and cultural determinants. ${ }^{\text {xwi }}$ There appear to be no cultures in which women do not suffer domestic abuse. Despite its prevalence, in some jurisdictions, domestic abuse has only recently been recognized as a human rights violation in some jurisdictions. ${ }^{\text {xwii }}$ In far too many states around the world, some cultural communities' tolerance for, if not downright endorsement of, domestic abuse remains legally unchallenged. ${ }^{\text {xix }}$

Many victims of domestic abuse bring an end to their suffering by leaving the relationship. However, it is widely acknowledged that many other not all-victims do not leave-se. There are a multitude of factors affecting victims' adaptive responses to their suffering and which offer generalised explanations for such apparently counter-intuitive behaviour. For many victims of domestic abuse the key obstacles to leaving are primarily material and include, economic dependency upon the abuser, the threat of homelessness, the lack of available shelters and refuges, and genuine fears for the effects of such disruption upon children and other family members. Put somewhat crudely, such obstacles might be compared with the so-called 'opportunity costs' which some point to as a recurring consideration for anyone eensidering contemplating leaving a relationship or community. ${ }^{\mathrm{ax}}$ Opportunity costs will influence someone's decision to leave but do but are not, by themselves, render someonea person unable to leave. understood as disabling the very capacity for exiting.

16 | P a g e 
A second ${ }_{2}$ and deeper level of obstacle is more overtly psychological and consists of many victims' identification with the role of a 'battered woman'. adaptive behaviour is not explained not primarily by reference to tangible material obstacles and forms of cost-benefit analysis. Rather, women are perceived as largely unable to leave as a consequence of rationalising their abuse as a comprehensible part of their lives and their fate. At this second level, cultural and religious factors mav influence victims' identification with the role of a battered woman, but they are not central to that process.

A third level of obstacle locates the psychological condition of the battered woman within an overtly cultural and religious context. A thorough understanding of the specific force of cultural and religious obstacles to women not leaving abusive partners entails an appreciation of just how deep are their effects. Specifically, the effects of culture and religion are particularly powerful in respect of disabling many married women's capacity to even initiate, let alone, effectively see through a commitment to leaving the relationship. While it is not present in all forms of domestic abuse, this third level of obstacle is of particular interest for this paper, given the extent to which it can effectively disable victims' capacity to leave. ${ }^{\text {sxii }}$

Various authors have examined the effects of culture and religion upon domestic abuse. ${ }^{\text {sxii }}$ An important factor concerns many victims' apparent acceptance of appeals to so-called 'higher loyalties'. As Ferraro and Johnson write, '(w)hen the appeal to higher loyalties is employed as a strategy to cope with battering, commitment to and involvement with an ideal overshadows the mundane reality of violence. ${ }^{\text {txii }}$ A Empirical evidence supports this claim. Specifically, the disabling effects of culture and religion are documented by two specific example of victims' reconciliation with domestic abuse can be found in worecent studies into the experiences of some women of South Asian descent, living within the United Kingdom. ${ }^{\text {xav }}$ Both studies identified a range of cultural and religious factors which explain victims' apparent prioritisation

Commented [FF20]: *One key question a reviewer would have is whether domestic abuse is thus more widespread in certain cultural communities, or less women in such situations try to leave them when they are part of certain cultural communities. Without differential effect of some form, the focus on culture seems undermotivated, and the idea of cultural harm (rather than other forms of harm) too. You need to demonstrate that these women are more trapped than women in different kind of cultural communities (or that all women are trapped because of their respective cultural communities). - This key issue remains to be addressed. 
of cultural and religious imperatives over their own immediate interests in avoiding the abuse.

Five different factors are identifiable within these studies.

(1) There exist cultural and religious barriers to women even initiating discussions about sexuality and thus, what may or not be appropriate behaviours within a sexual relationship.

(2) There exist cultural obstacles to victims' seeking help from within and outside the community, including well-founded fears of being excluded from the family and community if they reveal themselves to have been the victims of abuse.

(3) The vocabularies of many South Asian languages do not include terms for designating forms of specifically sexual abuse, severely restricting some women from even referring to their experiences as 'abuse'.

(4) There exists a widespread cultural expectation of female obedience to their menfolk, and victims of domestic abuse are liable to being dismissed or blamed for causing their own abuse by not being sufficiently obedient.

(5) The recurring cultural and religious mechanism underlying many of these barriers is the extremely powerful aversion to shame and dishonour prevalent within these communities generally. ${ }^{\mathrm{xx} i}$

As one of the reports states, "there is a tendency to prioritise protecting the "honour" of the community over the safeguarding of vulnerable girls... it does appear that silence in the name of avoiding shame and preserving honour, is allowing men to continue operating with impunity, therefore fuelling sexual violence against girls and women further., ${ }^{\text {xxwi }}$

Over $80 \%$ of the women studied in one of the reports explicitly referred to the fear of being disowned from-by their family and community if they reported the abuse they suffered. One victim stated, 'my own family didn’t let me disclose [the\} my-sexual violence _received]-from 
my husband and I was emotionally blackmailed by them saying that I have a big mouth and don't think about their reputation in the community. (They) also said that by religion you have to satisfy your husband's needs. ${ }^{\text {,axiii }}$

Another victim testified to the influence exerted by religious and cultural beliefs upon her own mother. She stated, 'I was experiencing sexual and domestic abuse from my husband, and disclosed to my mum in the hope that she loves me and will protect me. Instead I was shown the main door and was told that the door is closed to me forever. ${ }^{\text {,aix }}$

Finally, a Hindu victim of domestic abuse, from another report, described her conditions in the following terms: 'my culture is like my blood-coursing through every vein in my body. It is the culture into which I was born and where I grew up, which sees the woman as the honour of the house. In order to uphold this false 'honour' and 'glory' she is taught to endure many kinds of oppression and pain in silence. In addition, religion also teaches that her husband is her god. Fulfilling his every desire is her religious duty. A woman who does not follow this path in our society has no respect or place in it. She suffers from all kinds of slanders against her character; she has to face much hurt entirely alone. She is responsible not only for her husband but also for his entire family's happiness. ${ }^{{ }^{\prime}}$ The internalization of cultural practices and expectations constitutes a very powerful mechanism in many women's apparent reconciliation with an intolerable fate.

The right of exit has figured prominently in the arguments of some theorists who seek to reconcile a continuing commitment to a rights-based legal order with a respect for cultural diversity. The right appears to provide a means for pursuing the reformulation of human rights norms amidst diversity. Maintaining the right ensures that legislators don't simply capitulate to any and all ways of being and believing, but that the act of evaluating the acceptability of such ways is fundamentally accorded to individuals. In this way, the value of individual sovereignty 
may be upheldretained. However, all of this rests upon an assumption that individuals' capacity for initiating the right of exit is largely, if not entirely, immune from the effects of the cultures some individuals develop their identities within. Returning to our specific examples, it entails interpreting women's failure to seek to leave their communities as evidence that they continue to affirm the conditions they are exposed to. An alternative interpretation is that it is precisely their exposure to these particularly disempowering aspects of their cultural communities which accounts for why they do not leave, whilst simultaneously providing the basis for condemning, rather than condoning, those conditions. ${ }^{. \underline{i i}}$ However self-evidently true this may appear to some, it is actually a deeply controversial claim within the context of theoretical engagements with cultural diversity. After all, the claim suggests that public authorities have to be more vigilant of some cultural communities than they are of others. It also clearly implies that one cannot assume that the apparent choices of some members of some communities are sufficiently sovereign; $=\underline{0}$ One should, therefore, be cautious in proceeding down such avenues. the evidence above clearly challenges the assumption that procedurally upholding an individual right of exit provides sufficient insurance against forms of intra-cultural oppression and discrimination.

\section{Yes, but: cCountering objections and an alternative account of agency}

Various objections can be levelled at both my characterisation of culture, and of the victims of * domestic abuse. It could be argued that the account of cultural harm which I present ultimately rests upon an empirically false conception of cultural community. To be trapped inside something presumes the existence of some closed, static and homogenous construction, which has rigid and impermeable boundaries. On this view, culture is conceived of as a "window-less box" fromeut of which it is difficult for anyone, let alone vulnerable women, to exit.pass. The alternative to this view of culture is one which posits the inherent contingency and fluidity of all 
cultural communities. ${ }^{\text {div }}$ Separate cultures do obviously exist. ${ }^{\text {dk }}$ However, their boundaries overlap in a series of highly complex matrices, so that many individuals' identities will be significantly influenced by a broad range of cultural conditions. In these circumstances, exiting from one cultural community in order to enter others may often be a largely mundane act, which does not require elaborate or formal rites of passage.

While the anti-essentialists can, I believe, exaggerate the presumed fluidity and contingency of + Formatted: Left, Indent: First line: $0 \mathrm{~cm}$ all cultural communities, the key point can be acknowledged without thereby undermining the account of cultural harm presented here. Victims of domestic abuse will invariably pursue activities and relationships outside the realm of their immediate family and even the broader cultural community which is prepared to tolerate the abuse. They need not be entirely restricted to the single role of obedient wife to an abusive husband. However, some relationships and roles can be fundamentally constitutive of an individual's sense of self-worth, and thereby strike at the core of their capacities for agency. ${ }^{\text {dli }}$ For women in particular, $W_{\text {within }}$ some cultural communities for women in particular, being married is a condition of enjoying any form of recognition or status as a sufficiently mature member of the community. Where the status of being married grounds and, for some at least, ostensibly "validates" the treatment meted out by some husbands to their wives, it should not be difficult to see how this one relationship can be the source of so much harmful for some women. Of course, in many (but not all) cultures it is formally possible, at least, for women to initiate and secure a divorce without the prior approval of their husbands. In such communities, many women's formal exposure to the form of cultural harm I have outlined, will be much less, or, non-existent. That said, divorce equality, if we can phrase it so, remains a remote aspiration for vast numbers of women across the globe.

This does not necessarily entail that they are physically entrapped within some purportedly, utterly closed community, but rather that their freedom of deliberation and of movement are, 21 I P a g e 
none the less, effectively restricted as a consequence of who their cultures expect and require them to be. Identity-forming, and maintaining relations, may not, necessarily, exhaust all of an abused woman's activities and commitments, but may still have a significant impact upon core aspects of her identity and opportunities.

Another objection to my argument could be that it relies upon a conception of the victim as being unduly pacified by the cultural conditions which confront them. As a consequence, perhaps, of some saviour mentality on my part, I have been too quick to depict many such women as passive victims in need of outside help. In response, no one should under-estimate the devastating effects of domestic abuse upon its victims. Nor does one need to be dogmatically Millian in one's conception of what individual agency should entail, to raise legitimate objections to institutions which severely restrict many women's fundamental rights within marriage. However, the objection really has a deeper significance and which takes aim atspeaks to the account of agency my formulation of cultural harm presupposes, and which might be seen as unduly pacifying those the condition is applied to. As has already been briefly acknowledged above, there are many overt, external impediments to women seeking to exit or escape from abusive relationships, which are themselves, in some ways, tolerated by elements of the wider cultural communities in which they are located. My account of cultural harm, however, goes further in seeking to identify how some women's capacity to condemn and renounce such abuse, can itself be severely undermined by the cultural community from which their sense of self and identity is derived.

One reason why many victims of domestic abuse to do not seek to exit abusive relationships is, as we have seen, that they internalize a diminished role allocated to themethemselves. Some women come to evaluate their sense of self-worth and dignity through their experience of being abused. The greater the tangible obstacles are to leaving the relationship and the culture, the increased likelihood of this belief, eir doing so will obviously be increased the greater the
Commented [FF25]: Here you making a comparative claim. That's why earlier, you need to provide more evidence on the differential incidences and/or outcomes of domestic abuse in different cultures. 
tangible obstacles are to their leaving the relationship and the culture, although, of course, this diminished sense of self-worth and dignity can occur even where few such obstacles exist.

Exercising the right of exit entails the capacity for an individual to conceive of herself as an agent capable of initiating a course of action that is inherently critical of the community she seeks to exit. In many cases, this condition will entail an individual conceiving of herself as possessing a worth and dignity independently of her cultural community and the fate accorded to her within it. In many cases this is no doubt possible, but the extent to which many victims of domestic abuse do not seek exit, serves to remind us of the need to allow for the possibility that not all individuals will retain this sense of worth and dignity. In order to confront the intolerable, one must have a sufficiently intact sense of oneself as being someone who deserves to be treated better ${ }^{\text {xliii. }}$.

This line of argument raises a further possible objection to the account of cultural harm I have outlined, and addresses a deeper philosophical concern about the constituents of agency more generally. The prevailing view, within much of the literature concerning the political and legal regulation of intra-cultural relations, remains the conventional vision of a sovereign individual agent whose capacity for normative deliberation, as opposed to what is tangibly deliberated upon, cannot be determined or significantly undermined by the cultural environments they inhabit. On this view, to respect another agent is precisely to understand them as constitutive ends and not the mere marionettes of some or other cultural forces. Of course, there is a vast body of literature on this subject, andef course. Hhowever well-honed and practiced are the arguments supporting this conception of sovereign agency, one of the most interesting challenges entailed by affirmatively responding to cultural diversity precisely consists of the, at the very least, tacitly, alternative understanding of agency this approach rests upon. To this extent, the account of cultural harm outlined here trades uponpicks out what defenders of a right to cultural identity do and must acknowledge: that is, an appreciation of just changing the order. The greater the tangible obstacles are to their leaving the relationship and the culture, the increased likelihood of this belief, although this diminished etc

Commented [JF28]: Conceiving independently or independent of her cultural community 
how deep and significant are the effects of cultural community upon those who develop their identities within them. After all, a broader policy of respecting cultural communities is defended on grounds which range from the necessity of this policy for individuals' exercise of personal autonomy and enjoyment of equality, through to being essential for upholding the selfrespect and purportedly inherent dignity of those who draw so heavily upon their cultural communities for orienting their way in the world. None of these arguments hold that the effects of culture upon individuals can only ever be skin-deep. Cultural attributes such as race, religion, gender, and ethnicity are thus integral to the construction of many peoples' identities. In acknowledging this claim, one must at least countenance the possibility that some such attributes can constitute forms of harm as I have formulated that notion above. This is precisely what I have argued occurs in the case of domestic abuse and its effects upon some women's capacity to initiate exit from their circumstances. ${ }^{\text {xix }}$

\section{A Return to Human Rights}

I conclude by returning to briefly address the broader context of how human rights may respond to cultural diversity. Despite its continuing prevalence, domestic abuse is an acknowledged human rights violation. However, many victims do not seek to exit from the relationships and the wider cultural communities in which the abuse occurs. I have argued that, the fact that they don't do so, provides further support for some of the central claims made by defenders of the right to cultural identity; that culture can, and often does, have a deeply influential effect upon members' identities and sense of self-worth. While the vast majority of contributions to this literature focus upon the beneficial effects of culture's influence upon individuals, I have sought to show that this is not universally the case. Indeed, given the prevalence of domestic abuse and the extent to which many cultures do not unequivocally condemn and seek to end such treatment of women, there is good reason to include consideration of how culture can invidiously support harm.
Commented [FF30]: It strikes me as wrong or at least controversial to speak of 'class' as cultural attribute. Some might say something similar about "race" (and some would doubt that there is such an attribute as being of a different human race).

Commented [FF31]: *This still applies: That this abuse leads to incapacity (in this sense) needs to be strengthened. Currently, there is too little - mainly the quote from the Hindu woman and some reference to studies. This is suggestive, but not yet a demonstration. More conceptual analysis of the capacity would also be required - what does this capacity consist in and which elements of it are disrupted or completely disabled by what factors exactly?

Formatted: Line spacing: single

Formatted: Left
Commented [FF32]: *Again, this comment still applies: For you to demonstrate that these cultures cause harm (rather than "merely" let it happen) you need to make a much stronger case - including about differential outcomes and how these are not mere correlates to living in the cultures in question. 
The appeal of a right to exit for a normative approach which seeks maximal respect for many, if not all, of the world's cultures, in the name of a principle of respecting cultural diversity, is clear. Human rights defenders have been criticized on many occasions for advocating an alternative, more zealously interventionist policy towards "non-compliant" cultures. Responding effectively to the challenge of cultural diversity obviously entails the development of a far more sophisticated and nuanced approach to difference and to ostensive otherness. This paper has sought to contribute to that process of response and potential reform. Doing so from a perspective supportive of human rights requires, however, an extensive engagement with what a right to cultural identity may entail for some intra-cultural relations. Ultimately, a right to cultural identity cannot be a right to practice any formally-established cultural ways of being and believing, but rather to those which are compatible with, and supportive of, the self-respect and dignity of all of their members. Similarly, human rights cannot commit to defending cultural diversity as an end-in-itself, or what Kwame Appiah refers to as the 'diversity principle'. The value of any given culture should be evaluated by human rights defenders on the basis of whether or not any given culture genuinely respects all of its own members' sense of self-worth and dignity. A human rights-based approach to regulating cultural diversity cannot support cultural conditions which effectively entrap human beings within what Ralf Dahrendorf refers to as 'communities of fate'. 'Whatever one's view of the use and abuse of culture, it should be clear that any attempt to respond constructively to cultural diversity cannot be achieved by formulating regulative principles which would largely exclude concern for intra-cultural relations from the legitimate sphere of deliberation. 
' The paper thereby analyses the harmful potential of some cultural practices. The phenomenon of cultural harm remains largely overlooked in the literature, and warrants a comprehensive investigation. This paper focuses upon one of those aspects of cultural harm which is extensively researched, whilst acknowledging that its effects can extend to many other groups of victims.

ii See the American Anthropological Association's infamous 'Statement on Human Rights', American Anthropologist (1947), 49. Pp? For an insightful analysis of the controversial nature of that statement see K. Engle, (2001) 'From Skepticism to Embrace, Human Rights and the American Anthropological Association from 1947-1999', Human Rights Quarterly, 23 ? For an excellent analysis of the question of the alleged culturally specific character of human rights principles see R. Panikkar, (1982) 'I $s$ the Notion of Human Rights a Western Concept?', Diogenes, 120 ?? Interestingly, the UN General Assembly recently felt the need to recently reassert the universality of human rights principles. GA Resolution 67/1, 2012.

iii See in particular, Pollis, A. \& Schwab, P., (2000) 'Human Rights: A Western Construct with Limited Applicability', in Pollis, A. \& Schwab, P. Human Rights: New Perspectives, New Realities, (Boulder, Colorado: Lynne Rienner), pp. 1-18. Makau, Mutua, (2003) Human Rights: a Political and Cultural Critique, (Pennsylvania: University of Pennsylvania Press). See also his 'The Ideology of Human Rights', in Virginia Journal of International Law, (1996), 36. iv A number of theorists have pursued this approach. See Charles Beitz, The Idea of Human Rights (Oxford: Oxford University Press, 2009). Jack Donnelly, (2007) 'The Relative Universality of Human Rights', Human Rights Quarterly, 29:2, pp. 281-306. John Rawls The Law of Peoples (Cambridge, Mass.; Harvard University Press, 1999)

${ }^{\vee}$ See Fn. iii above.

vi 2007. Op cit.

${ }^{\text {vii }}$ A great deal of conceptual and historical analysis into the sheer-significance of identity for individual well-being was initiated by the so-called "politics of recognition" perspective. See Charles Taylor's publication Multiculturalism and the Politics of Recognition in Amy Gutmann (ed.) Multiculturalism: Examining the Politics of Recognition, (Princeton. N.J.: Princeton University Press, 1994), pp. 25-74.

viii For an example of the defence of such an account see Jeremy Waldron, 'Minority Cultures and the Cosmopolitan Alternative', University of Michigan Journal of Law Reform, 25: 1992, 751.

ix A number of theorists have argued for rights to cultural identity in these terms. See Bhiku Parekh, Rethinking Multiculturalism: Cultural Diversity and Political Theory, (2 ${ }^{\text {nd }}$. Edition), (Basingstoke: Palgrave, 2000). Avishai Margalit \& Moshe Halbertal, (2004) 'Liberalism and the Right to Culture', Social Research, 71:3: 529-548. Joseph Raz \& Avishai Margalit (1990).

'National Self-Determination', Journal of Philosophy, LXXXVII(9): 439-461. Joseph Raz, (1994), 'Multiculturalism: a Liberal Perspective', in his Ethics in the Public Domain: Essays in the Morality and Law of Politics, (Oxford: Clarendon Press), 155-76.

${ }^{*}$ Mutua Makau makes this argument. Op cit. p. 109.

${ }^{x i}$ Human Rights Council, Advisory Committee, 'Preliminary study on promoting human rights and fundamental freedoms through a better understanding of traditional values of humankind' (2012), A/HRC/AC/9/2.

Formatted: Highlight

Formatted: Highlight

Formatted: Highlight 
xi The phrase 'hoping for too much" is a reference to Joshua Cohen's 'Minimalism About Human Rights: the Most We Can Hope For? Journal of Political Philosophy, Vol. 12:2, 2004, pp. 190-213.

xiii See Fn. iii above and Cohen (2004) op cit.

xiv Charles Beitz (2009) op cit. pp.186-96 argues this.

${ }^{x v}$ The CEDAW Committee has addressed the issue of excessive reservations in four separate General Recommendations. Recommendations No. 4 (1987), No. 20 (1992), No. 21 (1994) and No. 28. ?

${ }^{x v i}$ A reference to two recent theses which herald the demise of what the respective authors consider to be the veritable hegemonic influence of human rights law. See Eric A. Posner, The Twilight of Human Rights Law (Oxford: Oxford University Press, 2014) and Stephen

Hopgood, The Endtimes of Human Rights (Ithaca: Cornell University Press, 2013).

wii The right of exit figures most prominently in Chandran Kukathas' attempt to reconcile liberalism with diversity. See his The Liberal Archipelago: A Theory of Diversity and Freedom, (Oxford: Oxford University Press, 2003). It also figures in the political theory advocated by Bhiku Parekh, op cit. and Will Kymlicka, op cit. Critics of the right include Leslie Green, op cit. and Avelet Shachar (2001) Multicultural Jurisdictions: Cultural Differences and Women's Rights (Cambridge: Cambridge University Press).

xvii My discussion focuses upon the possibility of individuals exiting communities within a single sovereign state. As I write, countless numbers of people are risking life and limb in their attempts to seek refuge in other countries. The right of exit has little purchase in this context ${ }^{\text {xix }}$ Parekh, op cit. David Ingram, (2013) 'Group Rights: a Defence' in Thomas Cushman, (ed.) Handbook of Human Rights, (New York: Routledge), pp. 277-290.

${ }_{x x}$ This remains core to any discussions of the philosophical grounding of human rights norms and testifies to the influence which liberal philosophy exerts upon human rights thinking.

xixi Amy Gutmann (1998) argues on these grounds. See her 'Freedom of Association: an Introductory Essay', in her Freedom of Association (Princeton: Princeton University Press), pp. 3-34.

xuixii Joseph Raz, op cit. defends the right of exit as a means for promoting personal autonomy. Brian Barry (2001) Culture and Equality: an Egalitarian Critique of Multiculturalism (Oxford: Polity) grounds a right of exit on the ideal of equality. In contrast, Chandran Kukathas, op cit. excludes both autonomy and equality as necessary ideals for liberalism and offers the most uncompromising formulation of a subjective approach to the right of exit.

xuii This sentence touches the tip of an intellectual ice-berg concerning an assumption that Makau, op cit. is one of the strongest advocates of this view.

xxiv Although this is to assume that such individuals will be able to relocate to communities or social environments in which a broader range of rights are recognised.

${ }_{\text {wwaw }}$ As Peter Jones writes, 'if cultures matter morally, it is because they matter to and for people and, if that is so, the issue of how people are to count morally must precede rather than follow our encounter with cultures.' Op cit. . 45. My own concerns reflect those of Peter Falk in his insistence that practices which have 'intolerable effects' upon their victims should not be included in any formulation of universal standards. See Falk, (1992), 'Cultural Foundations for the International Protection of Human Rights', in A.A. An-Na'im, (ed.) Human Rights in Cross-Cultural Perspectives: A Quest for Consensus, (Philadelphia: University of Philadelphia Press), p. 49.

${ }^{\text {xwi }}$ See Elizabeth Zechenter (1997) 'In the Name of Culture: Relativism and the Abuse of the Individual', Journal of Anthropological Research, 53; pp. 319-47. Carolyn Hayter (1996) 'Female Circumcision: is there a Legal Solution?', in P. Steiner and J. Alston (eds.) International Human Rights in Context, (Oxford: Clarendon Press). Arati Rao, (1995) 'The 
Politics of Gender and Culture in International Human Rights Discourse', in J. Peters and A. Wolper, (eds.) Human Rights: International Feminist Perspectives, (New York: Routledge), pp. $167-75$.

xxvii It has been estimated that within European countries, for example, one in four women experience domestic abuse during their lifetime, and between $6-10 \%$ of women in any given year. Within England and Wales during 2013/14, there were 1.2 million female victims of domestic abuse and it is estimated that around $30 \%$ of women will experience domestic abuse during their lifetimes. Council of Europe (2002) Recommendation of the Committee of Ministers to Member States on the Protection of Women Against Violence. Adopted on 30 April 2002; and Explanatory Memorandum. Strasbourg, France, Council of Europe.

wwii Rachel Pain, 'Everyday Terrorism: How Fear Works in Domestic Abuse', (Centre For Social Justice and Community Action, Durham University and Scottish Women's Aid, 2014); Oonagh Gay and John Bardens, Domestic Violence, (UK Parliament, Commons Library Standard Notice, Standard Notes SN06337, 2014); National Coalition Against Domestic Violence, (2014) Domestic Violence Factsheet. Accessed via http://www.ncadv.org/files/Domestic\%20Violence\%20Stylized--GS\%20edits.pdf.

xxviii For a summary of the legal recognition of domestic abuse as a crime see Andrew Fagan The Atlas of Human Rights: Mapping Violations of Freedom Around the Globe (Berkeley, CA.: University of California Press, 2010).

xxix Despite the UN General Assembly's Declaration on the Elimination of Violence Against Women. A/RES/48/104 (1993). Article 1 of which defines 'violence' as including psychological harm.

xx See Kukathas (2003) op cit. pp. 109-113 for a discussion of opportunity costs.

xxxi Thus, Lenore Walker has argued that many victims of domestic abuse do not leave because of a state of learned helplessness which results from enduring prolonged abuse. Some victims thereby begin to take on a role of the 'battered woman'. See her The Battered Woman Syndrome (New York: Springer, $3^{\text {rd }}$. edition, 2009). Others have criticised this approach for its alleged failure to duly engage with the structural and social factors in domestic abuse. See Edward Gondolf and Ellen Fisher (1988) Battered Women as Survivors: an Alternative to Treating Helplessness (Lexington, MA.: Lexington Press).

xxxii Clearly, many victims of oppressive conditions do challenge and fight against their 'fate'. However, not all do so and this third level of obstacle aims to address this. My analysis here has been significantly influenced by the literature on so-called adapative preferences. See Jon Elster, Sour Grapes: Studies in the Subversion of Rationality, (Cambridge: Cambridge University Press, 1985), Gary Becker, Accounting for Tastes, (Cambridge, Mass.: Harvard University Press, 1996), Onora O’Neill, 'Justice, Gender and International Boundaries', in Martha Nussbaum and Amartya Sen, (eds.), The Quality of Life (Oxford: Oxford University Press, 1993): 303-323. Cass Sunstein, 'Preferences and Politics', Philosophy and Public Affairs, 20:1, Winter, 1991: 3-34. James Griffin, Well-Being: its Meaning, Measurement and Moral Importance, Oxford: Clarendon, 1986). All of these authors posit the need to respond critically to expressed preferences and desires, in circumstances where there is a reasonable suspicion that the individuals' preferences may be understood as adaptive towards unjust conditions. Sunstein states that 'governmental interference with existing desires may be justified because of the origins of those desires.' ('Preferences and Politics': 12). He further states that 'respect for preferences that have resulted from unjust background conditions and that will lead to human deprivation or misery hardly appears the proper course for a liberal democracy.' (ibid.) The adaptive preferences perspective is supported by a range of psychological studies which demonstrate what initially appears as an irrational response by the oppressed and disadvantaged to their own plight. Rather than developing dispositional attitudes and beliefs which directly challenge the legitimising narratives which support the status quo, there is 
actually a marked tendency to accept and endorse these narratives so that, either no harm is perceived, or victims blame themselves for their plight. See Melvin Lerner's work on Just World Theory, Lerner, The Belief in a Just World: A Fundamental Delusion, (New York: Plenum, 1980) and Major and Schmader's studies into the cognitive construal processes which they describe as 'chronic belief systems.' See also Brenda Major and Toni Schmader, 'From Social Devaluation to Self-esteem: The Impact of Legitimacy Appraisals' in B. Major \& J. Jost (Eds.), Psychology of Legitimacy: Emerging Perspectives on Ideology, Justice, and Intergroup Relations. (Cambridge: Cambridge University Press, 2001): 177. All of which evokes Wilhelm Reich's famous question: 'what has to be explained is not the fact that the man who is hungry steals or the fact that the man who is exploited strikes, but why the majority of those who are hungry don't steal and why the majority of those who are exploited don't strike.' The Mass Psychology of Fascism, (third edition), trans. Vincent Carfango, (New York: Farrar Strauss Giroux, 1971):53.

xxxii See A. Horton, M. Wilkins \& W. Wright, Women who ended abuse: what religious leaders and religion did for these victims. In A. Horton \& J. Williamson (eds.) Abuse and Religion, (Lexington, MA.: Lexington Books, 1988), pp. 235-245.

xairxaiv Ibid., pp. 330-31.

"uvv See Muslim Women's Network UK, Unheard Voices: the Sexual Exploitation of Asian Girls and Young Women, (2013) and Manjit Rehal and Sylvia Maguire, The Price of Honour: Exploring the Issues of Sexual Violence Within South Asian Communities in Coventry, (Coventry Rape and Sexual Abuse Centre, 2014). Both reports studied a number of women and other community members extending across Hindu, Muslim and Sikh religious communities and were authored by women from these communities. To reiterate, domestic violence is a global phenomenon and certainly is not only restricted to women of nonEuropean descent. I have chosen to specifically focus upon women of South Asian descent for several reasons: firstly, that many of them are immigrants into European countries (or the children of immigrants) and, combined with their ethic status, typically experience a greater sense of isolation from the wider community, which is a condition envisaged by the liberal archipelago. Secondly, that women from several religious communities, specifically including the Hindu, Muslim and Sikh communities, are nevertheless united in their exposure to a prevailing patriarchal set of beliefs and customs, which, although not universally endorsed within such communities, are formally upheld by recognizable tenets of these communities. Finally, that such women are also united in their exposure to the specific phenomenon of shame and dishonour which plays a highly significant role within a wider environment, one that serves to disable women's ability to combat their abuse.

${ }_{\text {xwi }}$ Cultures undoubtedly change and are not entirely static. However, some core elements of some cultures appear more resistant to change, which is clearly the case with the aversion to shame and dishonour within many such communities. For a highly detailed and sophisticated philosophical analysis of the social regulation of meaning see Lawrence Lessig, The Regulation of Social Meaning, University of Chicago Law Review, 62:3 (1995): 943-1045.

sxwii Unheard Voices, p. 28.

sxwii The Price of Honour, p. 10.

waix Ibid., p. 11.

Cited in Gita Saghal (1992), 'Secular Spaces: the Experiences of Asian Women Organizing', in G. Saghal \& N. Yuval-Davis, (eds.) Refusing Holy Orders: Women and Fundamentalism in Britain, (London: Virago Press), 196-97, p. 188. This quotation comes from a woman who killed her husband after enduring ten years of physical abuse. It is important to iterate that the testimonies of the victims presented above are not claimed to provide the essential truth about such communities. After all, there are far more families in which domestic abuse and sexual assault do not occur. What they are intended to show is how powerful, for some, is the 
perception that culture and religion serve to restrict women testifying to their abuse or, for current purposes, working to prevent women from electing to leave in order to avoid their suffering.

xli It is important to stress at this point that my choice of the focus upon women, and the subsequent critique I outline, does not explicitly entail or depend upon, the kind of essentialist vision most readily associated with Susan Moller Okin's ground-breaking contribution to the debate surrounding the effects of multiculturalism upon women. See her "Is Multiculturalism Bad for Women?" Boston Review, 22, (1997): 25-28. My own position is closer to the more nuanced account of women's identities and interests expounded by Ayelet Shachar,

Multicultural Jurisdictions: Cultural Differences and Women's Rights, (Cambridge: Cambridge University Press, 2000). Still, I am more concerned than Shachar about the potential of cultural conditions to colonize some individuals' sense of self.

xlii As Leslie Green writes, 'it is risky, wrenching and disorienting to have to tear oneself from one's religion or culture; the fact that it is possible to do so does not suffice to show that those who do not manage to achieve the task have staved voluntarily.' 'Internal Minorities and Their Rights', Will Kymlicka (ed.) The Rights of Minority Cultures, (Oxford: Oxford University Press, 1995), pp. 257-71: 266. Note however that my account of this third level of obstacle goes bevond Green's understanding of obstacles to exit.

xliii Some theorists such as, for example, Bhiku Parekh (op cit.) argues that we should never proceed down such paths since to do so is fundamentally disrespectful towards such cultures.

xliv One of the first and most powerful challenges to this traditional, window-less box, concept of culture was articulated by Clifford Geertz, The Interpretation of Cultures, (New York: Basic Books, 1973). For an excellent discussion of how various concepts of culture have affected legal and political approaches to cultural diversity, see Sunder, op cit.

xiv After all, if they did not, what would the right to cultural identity actually protect in any specific instance?

vki Various authors have stressed the importance of self-worth to human well-being. See Paul Benson, for example. See his 'Free Agency and Self Worth', Journal of Philosophy, 91:12, (Dec. 1994): 650-668. See also Catriona Mackenzie, 'Imagining Oneself Otherwise', in

Mackenzie and Stoljar, (eds.) Relational Autonomy, 124-150.

xvii Thus, it would be possible for a woman to be said to suffer from significant forms of cultural oppression, to the extent that these primarily impact upon her status as a married or marriageable woman, in cultures where being married is a key, but not exclusive, component of her identity and of her subsequent options and opportunities. It should be pointed out that my specific focus here is upon the possible existence of forms of oppression which have a discernible cultural basis and character, which suggests a particular formal and identifiable set of attributes. It is reasonably conceivable, specifically in respect of domestic abuse, that many women are also similarly 'disabled' by the abuse they suffer, and are similarly unable to resist their suffering, but where the underlying causes of the abuse are less discernibly or singularly cultural.

skiii As Mackenzie, op cit. p. 140 writes, 'without a sense of her own worthiness as an agent and of the worthiness of her capacities, her desires, and her beliefs, an agent will not be able to conceive of herself as capable of effective action.'

xlixxix Parekh exemplifies an understanding of culture as deeply influential upon the construction of individuals' identities. However, he insists that harm can only occur if individuals experience it in these terms as 'harm'. He even applies this test to cases of female genital mutilation. Op cit. . 275 .

'Kwame Anthony Appiah (2005) The Ethics of Identity (Princeton: Princeton University Press), p. 150 . 
ii Ralf Dahrendorf, Life Chances: Approaches to Social and Political Theorv, (Chicago:

Chicago University Press, 1979), p. 10.

Formatted: Font: Baskerville Old Face, 12 pt

31 | $\mathrm{P}$ a g e 